\title{
DESIGN OF REINFORCED CONCRETE LEDGE BEAMS - SAFETY AND ECONOMY
}

\author{
Mohammed H. Hedia ${ }^{1}$, Salah E. El-Metwally ${ }^{2}$, Ahmed M. Yousef ${ }^{3}$ \\ ${ }^{1}$ Teaching Assistant, ${ }^{2,3}$ Professor of Concrete Structures \\ Structural Engineering Department, Mansoura University, El-Mansoura, Egypt
}

\begin{abstract}
Safety is the key objective in structural design; however, for economy design optimization becomes an important issue. This paper looks at these two points which may seem to contradict, and tries to draw a line in order to help designers. The subject of this investigation is ledges in inverted-T beams. For safety, the strutand-tie model as a lower bound solution contributes to the development of safe design. The nonlinear finite element as an analytical tool helps to guide designers in deciding on the optimum performance of a given design. With two tools a designer can realize where a given design stands from safety and efficiency.
\end{abstract}

\section{Introduction}

Structural design aims to achieve different objectives, where safety comes on the top, other objectives, such as economy, are important too. Very often there are no single design tools that can help to achieve all design targets and hence different tools have to be utilized. In this paper, two promising tools are considered for the design of very important structural element, ledge in inverted-T beams. The tools are the strut-and-tie method, STM, for safe design and the nonlinear finite element analysis, NFEA, for optimization of structure efficiency.

In buildings, garages and bridges, the use of inverted-T beams for supporting girders allows for the overall system height to be reduced as compared with typical rectangular bent caps. This results in increased clearance underneath the bents and can lead to more attractive bridges or structures, by keeping the visible size of these supporting elements to a minimum.

The behavior of the ledge of inverted-T beams represents a major issue in the design of this supporting system. This is due the loading condition on the ledges; the path of loads through inverted-T beams is more difficult than in the rectangular bent caps. The bridge girder loads applied to the ledge flow in the transverse direction to the bottom of the web, then vertically to the top (compression) chord and finally along the length of the beam to the supports. These three-dimensional forces generate regions of stress discontinuities that are typically designed using either empirical equations or STM while it is better to predict performance, capacity and other detailed information about the beam, using 3D NFEA.

In this paper, the two proposed tools are utilized to examine the behavior of experimentally tested specimens in order to show and demonstrate how each tool can be utilized during the process of structural design. The tests have been carried out by Larson et al. (2013) at University of Texas at Austin. For the STM, the ACI 
318-14 strength coefficients are used. In performing the 3D NFEA, the software ABAQUS is employed.

\section{Strut-and-Tie Strength Factors}

In this paper, the ACI 318-14 code failure criteria for STM are employed, which is illustrated next with reference to the model in Fig. 1.

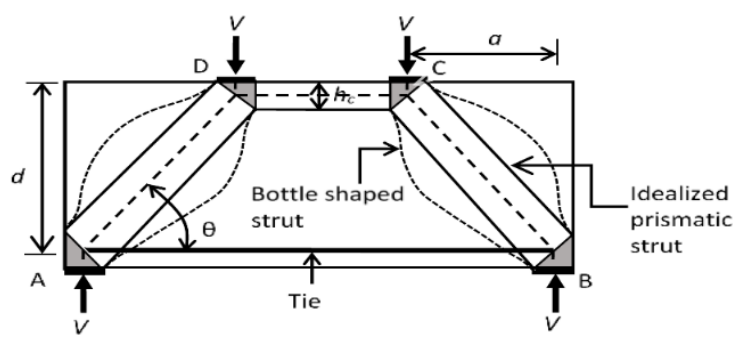

Fig. 1: Components of a STM of deep beam.

\subsection{Strength of Struts}

According to the ACI 318-14, the nominal compressive strength of a strut without longitudinal reinforcement, $F_{n s}$, shall be taken as

$F_{n s}=f_{c e}^{s} A_{c s}$

Where, $f_{c e}^{s}$ : is the smaller of the effective compressive strength of the concrete in the strut or the effective compressive strength of the concrete in the nodal zone, and $A_{c s}$ is the cross-sectional area at one end of the strut. In calculating $A_{c s}$, the strut width is measured in perpendicular to the strut axis at its end.

The effective compressive strength of the concrete in a strut $f_{c e}^{s}$ can be obtained from

$f_{c e}^{s}=0.85 f_{c}^{\prime} \beta_{s}$

Where, $f_{c}^{\prime}$ : is the concrete cylinder strength and $\beta_{s}$ is the effectiveness factor of concrete. Table 1 shows the values of $\beta_{s}$ according to the ACI 318-14 code, in which the stress conditions, strut geometry, and the angle of cracking surrounding the strut are reflected.

Table 1: ACI 318M-14 Code values of coefficient $\underline{\beta}_{s}$ for struts

\begin{tabular}{ll}
\hline Strut condition & $\beta_{s}$ \\
\hline
\end{tabular}

- A strut with constant cross-section along its length.

- For struts located such that the width of the midsection of the strut is larger than the width at the nodes (bottle-shaped struts):

a) With reinforcement normal to strut center-line to resist the transverse tension. $\quad 0.75$

b) Without reinforcement normal to the center-line of the strut. $0.6 \lambda$

-For struts in tension members, or the tension flanges of members. $\quad 0.40$

•For all other cases. $\quad 0.6 \lambda$

Where, $\lambda$ : is a modification factor to account for the use of lightweight concrete. $\lambda=$ 0.85 for sand-lightweight concrete, 0.75 for all-lightweight concrete, and $\lambda=1.0$ for normal weight concrete.

The design of struts shall be based on $\Phi F_{n s} \geq F_{u s}$, where $F_{u s}$ is the largest factored force acting in a strut and obtained from the applicable load combinations 
and the $\Phi$ factor is the material strength reduction factor which is equal to 0.75 for ties, struts, and nodes according to the ACI-318-14 Code.

\subsection{Nodal Zones}

Smeared nodes do not need to be checked if the reinforcement is properly developed until the extremities of the stress field. However, a check of the concrete stresses in the singular nodes is essential because of the stress concentration at these regions. The nominal compressive strength of a nodal zone, $F_{n n}$, shall be

$F_{n n}=f_{c e}^{n} A_{n z}$

where $f_{c e}^{n}$ is the effective compressive strength of the concrete in the nodal zone and $A_{n z}$ is the area of each face of the nodal zone and shall be taken as the smaller of the area of the face of the nodal zone perpendicular to the line of action of $F_{u s}$ or the area of a section through the nodal zone perpendicular to the line of action of the resultant force on the section.

The effective compressive strength of the concrete in a nodal zone, $f_{c e}^{n}$, can be obtained from:

$f_{c e}^{n}=0.85 f_{c}^{\prime} \beta_{n}\left(\right.$ or $\left.0.67 f_{c u} \beta_{n}\right)$

where $\beta_{n}$ is the effectiveness factor of the nodal zone. Table 2 shows the effectiveness factor, $\beta_{n}$, for nodal zones, ACI 318-14 Code.

Table 2: ACI 318-14 Code values of coefficient $\beta_{n}$ for nodes .

\begin{tabular}{lc}
\hline Nodal zone & $\beta_{n}$ \\
\hline For nodal zones bounded by struts or bearing areas or both, C-C-C node. & 1.00 \\
Nodal zones anchoring one tie, C-C-T node. & 0.80 \\
Nodal zones anchoring two or more ties with the presence of one strut, C-T-T node. & 0.60 \\
Nodal zones anchoring ties only, T-T-T node. & 0.40 \\
\hline
\end{tabular}

\subsection{Reinforced Ties}

The nominal strength of a tie, $F_{n t}$, shall be taken as $F_{n t}=A_{s t} f_{y}$; where $A_{s t}$ is the area of steel and $f_{y}$ is the yield stress. The width of a tie is to be determined to satisfy safety for compressive stresses at nodes. Depending on the distribution of the tie reinforcement, the effective tie width $w_{t}$ may vary between the following values but with an upper limit $w_{t, \max }$.

- In case of using one row of bars without sufficient development length beyond the nodal zones as shown in Fig. $2 \mathrm{a}$ : $w_{t}=0.0$

- In case of using one row of bars and providing sufficient development length beyond the nodal zones for a distance not less than $2 c$, where $c$ is the concrete cover as shown in Fig. $2 \mathrm{~b}: w_{t}=n \emptyset_{\text {bar }}+2 c$, where $\phi_{\text {bars }}$ is the diameter of the reinforcing steel.

- In case of using more than one row of bars and providing sufficient development length beyond the nodal zones for a distance not less than $s / 2$, where $s$ is the clear distance between bars, Fig. $2 c: w_{t}=n \emptyset_{\text {bar }}+2 c+(n-$ 1) $s$, where $n$ is number of reinforcement rows. 
In the three cases of Fig. 2, the development length according to the ACI 318-14, $l_{\text {anc }}$, begins at the intersection of the centroid of the bars in the tie and the extensions of the outlines of either the strut or the bearing area.

As for the upper limit of the strut width, $w_{t, \max }=\frac{F_{n t}}{b f_{c e}^{n}}$

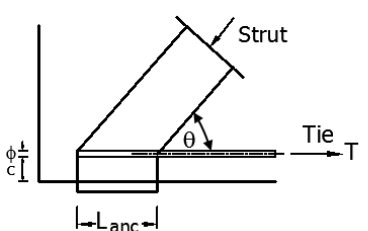

(a) $\mathrm{w}_{\mathrm{t}}=0.0$

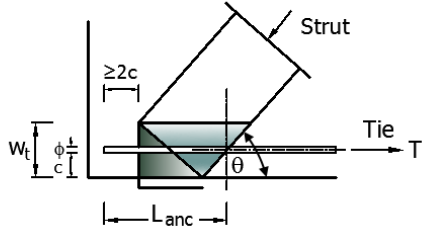

(b) $\mathrm{w}_{\mathrm{t}}=\phi_{\text {bars }}+2 \mathrm{c}$

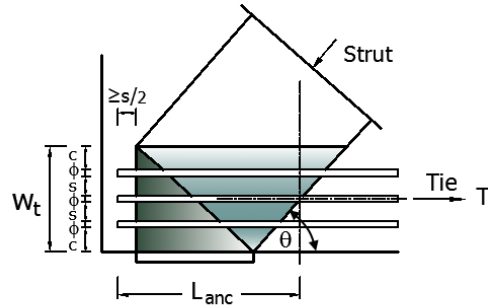

(c) $w_{t}=n \phi_{\text {bars }}+2 c+(n-1) s$

Fig. 2: The width of tie, $\underline{w}_{t}$, used to determine the dimensions of the nodal zone.

\section{Nonlinear Finite Element Analysis, NFEA, using Abaqus software}

\subsection{Finite Element Modeling}

Herein, the 3-D solid continuum element C3D8R is utilized to model concrete. This element is 8-noded linear brick having 3 translational degrees of freedom at each corner node as shown in Fig. 3a. The reinforcing steel is modeled as individual truss elements with steel material properties and cross sections using element T3D2; 2-noded 3D truss element as shown in Fig. 3b. The elements are embedded in the concrete using constrain called Embedded Region available in ABAQUS.

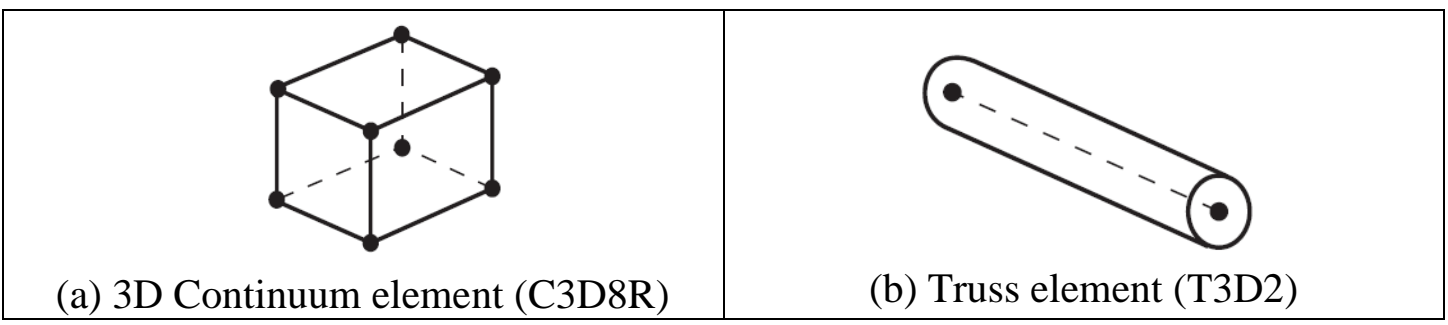

Fig. 3: Adopted element models for concrete and reinforcement (Abaqus 6.14, 2016).

\subsection{Modeling of Concrete Material}

Chaudhari and Chakrabarti (2012) recognized that concrete under low confining pressure acts in a brittle manner and the main failure mechanisms are cracking in tension and crushing in compression. If the confining pressure is adequately large to prevent the crack, concrete displays ductile behavior. The damage in quasi-brittle materials can be defined by evaluating the dissipated fracture energy required to generate micro cracks. Hence, the concrete damage plasticity model of concrete in ABAQUS software is adopted.

Fig. 4 shows the compression and tension response of concrete, where the unloading response of concrete sample is soft, due to the damage and hence the reduction of the material elastic stiffness. Two damage variables are used to identify the degradation of elastic stiffness, $\mathrm{d}_{\mathrm{c}}$ andd $\mathrm{d}_{t}$, the subscripts $\mathrm{c}$ and $\mathrm{t}$ refer to compression and tension, respectively. These parameters can take values from zero to one (zero for undamaged material and one for fully damaged). $E_{0}$ is the elastic 
stiffness of material and $\varepsilon_{c}^{\sim p l}, \varepsilon_{t}^{\sim p l}, \varepsilon_{c}^{\sim i n}, \varepsilon_{t}^{\sim i n}$ are the compressive plastic strain, tensile plastic strain, compressive inelastic strain and tensile inelastic strain. Using the initial elastic stiffness of concrete, Eqs. (1) and (2) can be used to model the stress-strain relation (Sümer and Aktaş, 2015).

$\sigma_{c}=\left(1-d_{c}\right) \cdot E_{0} \cdot\left(\varepsilon_{c}-\varepsilon_{c}^{\sim p l}\right)$

$\sigma_{t}=\left(1-d_{t}\right) \cdot E_{0} \cdot\left(\varepsilon_{t}-\varepsilon_{t}^{\sim p l}\right)$

To recognize the failure yield surface, cohesion stresses are used, Fig. 5. The effective cohesion compression and tension stresses can be computed from Eqs. (3) and (4) (Sümer and Aktaş, 2015).

$\bar{\sigma}_{c}=\frac{\sigma_{c}}{\left(1-d_{c}\right)}=E_{0} \cdot\left(\varepsilon_{c}-\varepsilon_{c}^{\sim p l}\right)$
$\bar{\sigma}_{t}=\frac{\sigma_{t}}{\left(1-d_{t}\right)}=E_{0} \cdot\left(\varepsilon_{t}-\varepsilon_{t}^{\sim p l}\right)$

In the compression stress-strain curve, ABAQUSE takes the inelastic strain as an input and changes it to plastic strain according to Eqs. (5) to (7) (Sümer and Aktaş, 2015).

$\varepsilon_{c}^{\sim i n}=E_{0} \cdot\left(\varepsilon_{c}-\varepsilon_{c o}^{\sim e l}\right)$

where

$\varepsilon_{c o}^{\sim e l}=\frac{\sigma_{c}}{E_{0}}$

$\varepsilon_{c}^{\sim p l}=\varepsilon_{c}^{\sim i n}-\frac{d_{c}}{\left(1-d_{c}\right)} \frac{\sigma_{c}}{E_{0}}$

The damage parameter $d_{c}$ can be obtained using Eq. (8) (Sümer and Aktaş, 2015).

$d_{c}=\frac{f_{c}^{\prime}-f_{c}}{f_{c}}$

After cracks initiate the load is transferred across cracks through the reinforcing steel bars, so modeling of tension stiffening is a must for accepted simulation. In CDP, modeling of tension stiffening can be specified by the stressstrain relation after peak stress, $\sigma_{t 0}$ or by applying fracture energy approach where the amount of energy used to open a unit area of crack is considered as a material property. This latter approach is used in this work

Fracture energy $\left(\mathrm{G}_{\mathrm{f}}\right)$ can computed from Eq. (9) (Tao et al., 2013).

$G_{f}=\left(0.0469 d_{\max }^{2}-0.5 d_{\max }+26\right)\left(\frac{f_{c}^{\prime}}{10}\right)^{0.7} \mathrm{~N} / \mathrm{m}$

where $f_{c}^{\prime}$ is in $\mathrm{MPa}, d_{\max }$ is the maximum coarse aggregate size (in mm) 


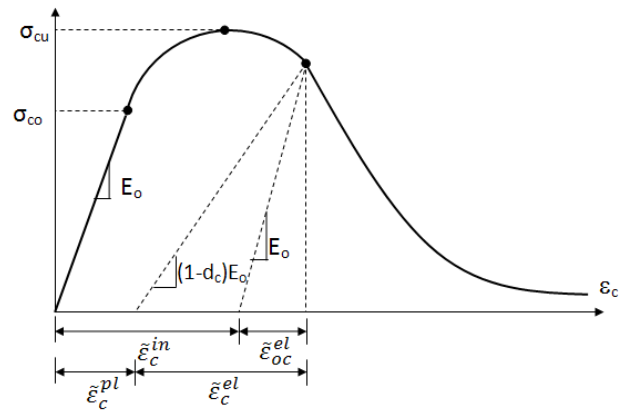

(a) Compression

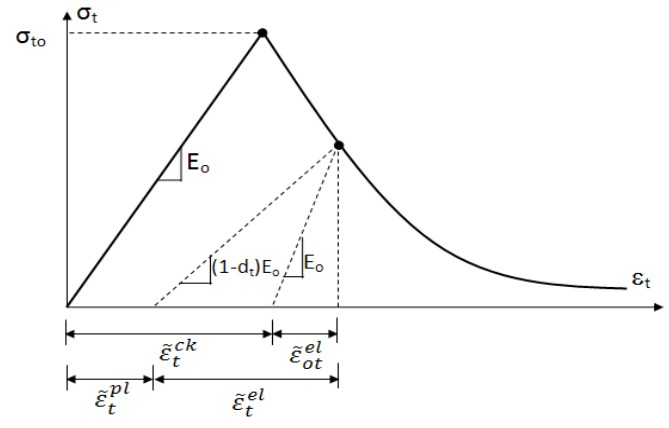

(b) Tension

Fig. 4: Behavior of concrete in compression and tension (Abaqus 6.13, 2015).

CDP needs some important parameters to be input in the software ABAQUS to make a real simulation of the concrete. These parameters stand for the triaxial compressive test of concrete which are five parameters and defined in DruckerPrager plastic flow function and yield function proposed that shall be taken as : dilation angle $\psi$ which can be taken $=31$ degrees, eccentricity could be taken $=0.1$, the ratio of biaxial compressive strength to uniaxial compressive strength $^{\sigma_{c 0}} / \sigma_{b 0}=1.12$ as shown in Fig. 5, viscosity parameter which shall be taken as default of the program, and the ratio of second stress invariant on the tensile meridian to that of the compressive meridian $K_{c}=2 / 3$ according to Jankowiak and Lodygowski (2004).

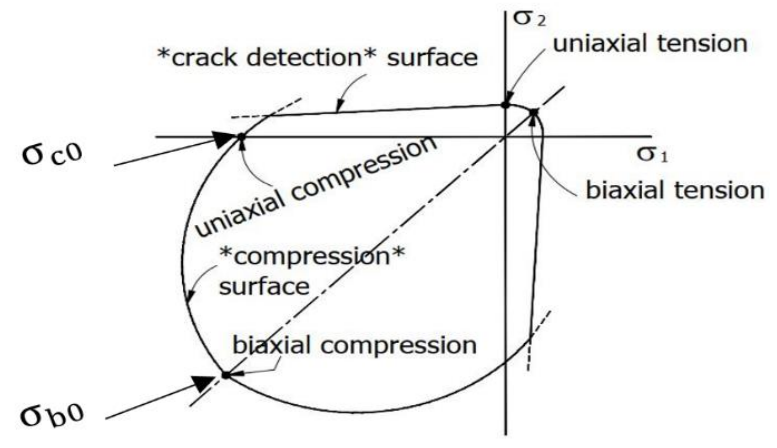

Fig. 5: Yield and failure surfaces in plane stress.

\subsection{Reinforcing Steel Modeling}

The steel reinforcement is modeled as an elastic-perfectly plastic material in both tension and compression.

\subsection{Bond between Concrete and Reinforcement}

In this analysis, a full bond between concrete and reinforcement is assumed. This assumption is implemented by the use of a constraint called embedded element (Abaqus, 2015). Reinforcement is embedded into the host elements, concrete, so that all embedded element's nodes have the same translational degrees of freedom as the concrete host element's nodes. 


\section{Tested Specimens}

In this study, five full-scale normal strength reinforced concrete inverted-T beams (SS1-75-1.85-06, SS1-75-2.5-06, SS1-75-2.5-03, SS1-42-2.5-03 and SS1-42-1.8503) subjected to concentrated loads on the ledges are considered. The specimens had been tested at the University of Texas at Austin's Phil M. Ferguson Structural Engineering Laboratory by Larson et al. (2012). To differentiate between the specimens, the nomenclature presented in Fig. 6 has been adopted.

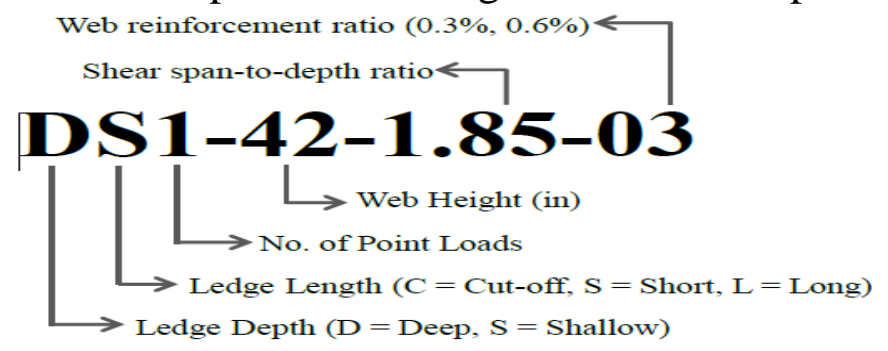

Fig. 6: Specimen nomenclature [2].

The Details of specimens are extracted from Larson et al. (2012) and Garber et al. (2017) and the full reinforcement details are presented in high accuracy in (Fernández-Gómez, 2012). Fig. 7 illustrates the dimensions of ledges in the specimens and the positions of the load bearing pads. In all the specimens, the distance from the midpoint of load plate to the edge of the ledge is $c_{1.85}=35.5 i n(901.7 \mathrm{~mm})$ and $c_{2.5}=34.0 \mathrm{in}(863.6 \mathrm{~mm})$ for short ledges while $\mathrm{c}_{1.85}=\mathrm{c}_{2.5}=3 \mathrm{in}(76.2 \mathrm{~mm})$ past the bearing end for the cutoff ledges. The reinforcement details are illustrated in Table 3 and Fig. 8.

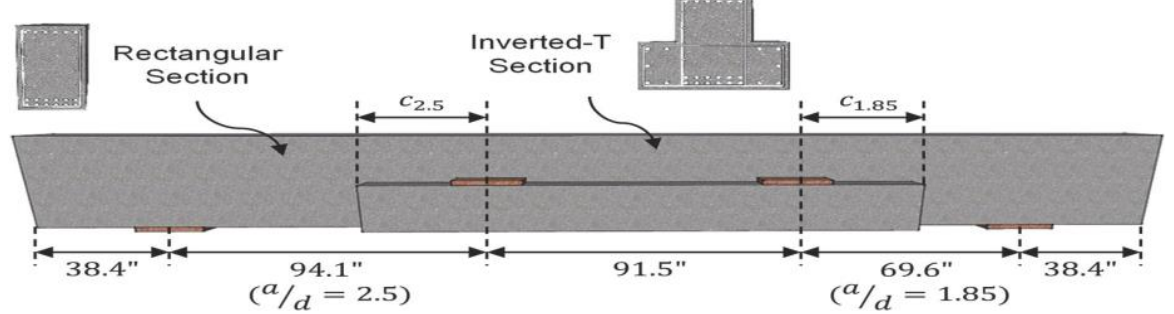

Fig. 7: Details of geometry for 42 in depth specimen.

Table 3: Details of reinforcement (Garber, et al., 2017)

\begin{tabular}{|c|c|c|c|c|c|c|c|c|c|}
\hline \multirow{2}{*}{$\begin{array}{c}\text { Specimen } \\
\#\end{array}$} & $\begin{array}{c}f_{c}^{\prime}, k s i \\
(\mathrm{MPa})\end{array}$ & \multicolumn{4}{|c|}{ Ledge reinforcement } & \multicolumn{4}{c|}{ Hanger reinforcement } \\
\cline { 3 - 10 } & $\begin{array}{c}A_{s l}, \text { in }^{2} \\
\left(\mathrm{~mm}^{2}\right)\end{array}$ & $\begin{array}{c}f_{y l}, k s i \\
(\mathrm{MPa})\end{array}$ & $\begin{array}{c}s_{\text {ledge }}, \text { in } \\
(\mathrm{mm})\end{array}$ & $\begin{array}{c}w_{\text {ledge }}, \text { in } \\
(\mathrm{mm})\end{array}$ & $\begin{array}{c}A_{\text {sh }}, \text { in }^{2} \\
\left(\mathrm{~mm}^{2}\right)\end{array}$ & $\begin{array}{c}f_{\text {yh }}, \text { ksi } \\
(\mathrm{MPa})\end{array}$ & $\begin{array}{c}s_{\text {hanger }}, \text { in } \\
(\mathrm{mm})\end{array}$ & $\begin{array}{c}w_{\text {hanger }}, \text { in } \\
(\mathrm{mm})\end{array}$ \\
\hline SS1-75- & 5.9 & 0.31 & 73.2 & 3.50 & 63.8 & 0.44 & 62.0 & 3.50 & 63.8 \\
$1.85-06$ & $(40.7)$ & $(200)$ & $(448)$ & $(88.9)$ & $(1621)$ & $(284)$ & $(427)$ & $(88.9)$ & $(1621)$ \\
\hline SS1-75- & 6.4 & 0.31 & 61.5 & 3.00 & 63.8 & 0.44 & 66.5 & 3.00 & 63.8 \\
$2.5-06$, & $(44.1)$ & $(200)$ & $(500)$ & $(76.2)$ & $(1621)$ & $(284)$ & $(459)$ & $(76.2)$ & $(1621)$ \\
\hline SS1-75- & 5.5 & 0.31 & 63.6 & 1.75 & 63.8 & 0.44 & 63.8 & 1.75 & 63.8 \\
$2.5-03$ & $(37.9)$ & $(200)$ & $(439)$ & $(44.5)$ & $(1621)$ & $(284)$ & $(440)$ & $(44.5)$ & $(1621)$ \\
\hline SC1-42- & 4.3 & 0.31 & 66.0 & 2.50 & 32.0 & 0.44 & 64.0 & 2.50 & 32.0 \\
$1.85-03$ & $(29.6)$ & $(200)$ & $(455)$ & $(63.5)$ & $(813)$ & $(284)$ & $(441)$ & $(63.5)$ & $(813)$ \\
\hline SC1-42- & 4.3 & 0.31 & 68.7 & 3.00 & 32.0 & 0.44 & 71.4 & 3.00 & 32.0 \\
$2.5-03$ & $(29.6)$ & $(200)$ & $(474)$ & $(76.2)$ & $(813)$ & $(284)$ & $(492)$ & $(76.2)$ & $(813)$ \\
\hline
\end{tabular}




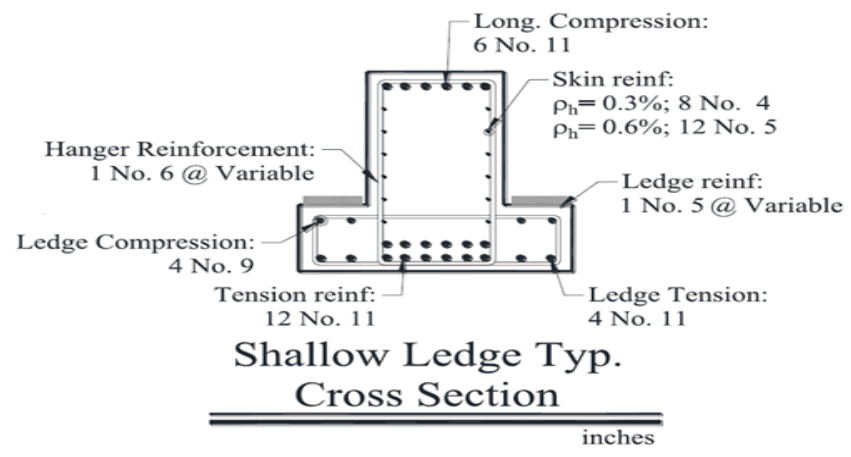

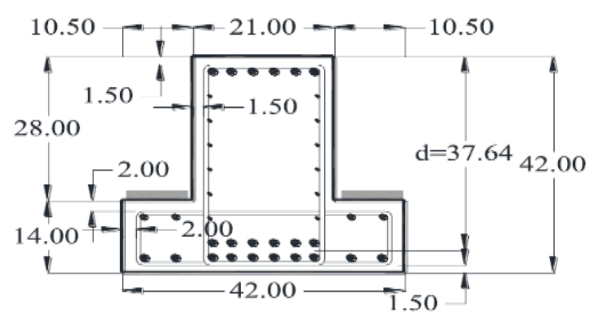

Shallow Ledge Typ. Cross Section

(a) 42in depth specimen
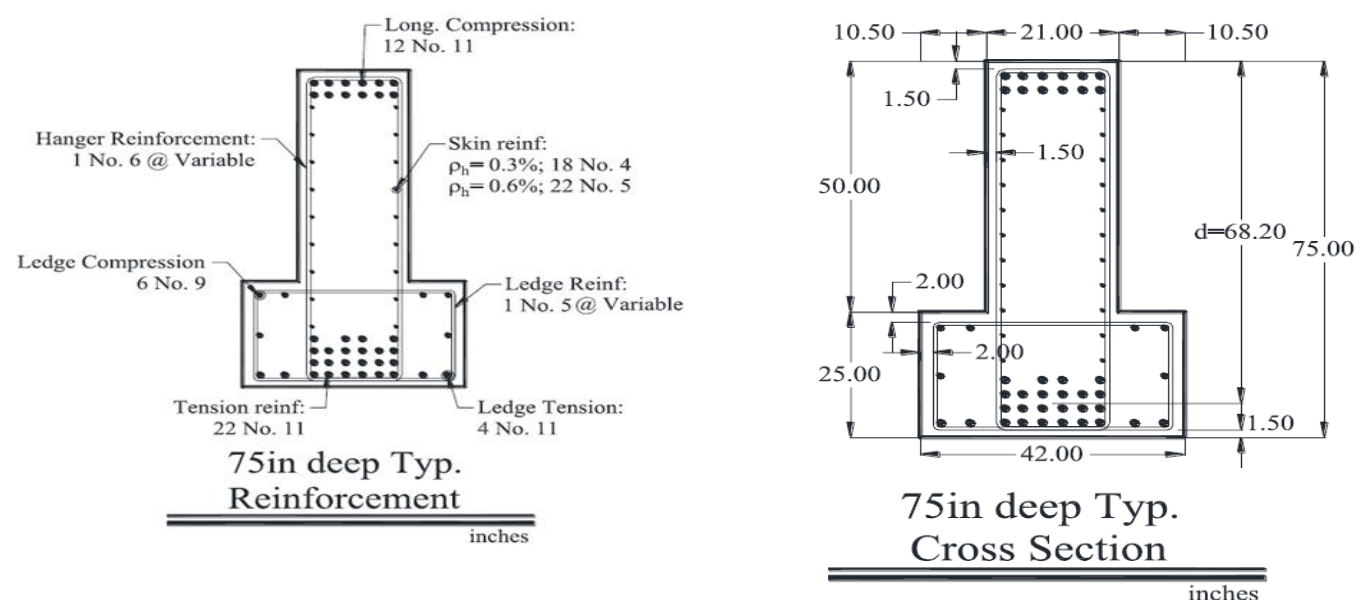

(b) 75in depth specimen

Fig. 8: Details of steel reinforcement of (a) 42in and (b) 75in depth specimens

\section{STM of Tested Specimens}

Inverted-T beams transfer the ledge load in three dimensions with the following sequence: firstly, from the flanges to the web, from the tension chord to the compression side, and afterwards to the supports. To recognize this behavior, it is important to consider a three-dimensional strut-and-tie model. For simplicity, the model is divided into two compatible two-dimensional models which are longitudinal and transverse STMs.

\subsection{Geometry of the Longitudinal STM}

An example of a simple longitudinal STM for an inverted-T beam with two shear spans is shown in Fig. 9, where each tie is aligned with the centroid of the reinforcing bars. Vertical hanger bars are placed at each load point with the tie corresponding to the center of the bearing pad. The number of hangers is equal to the number of loading points. A 45-degree spread on the ledge under the loading plates defines the width of hanger ties. For cut-off ledges, the load spread is limited on one side, as shown in Fig. 9.

The horizontal tie along the bottom of the beam is aligned with the centroid of the flexural reinforcement. The height of the tie is assumed to be twice the 
distance from the extreme tension fiber to the centroid of the steel as shown in the detail of Node A in Fig. 10.

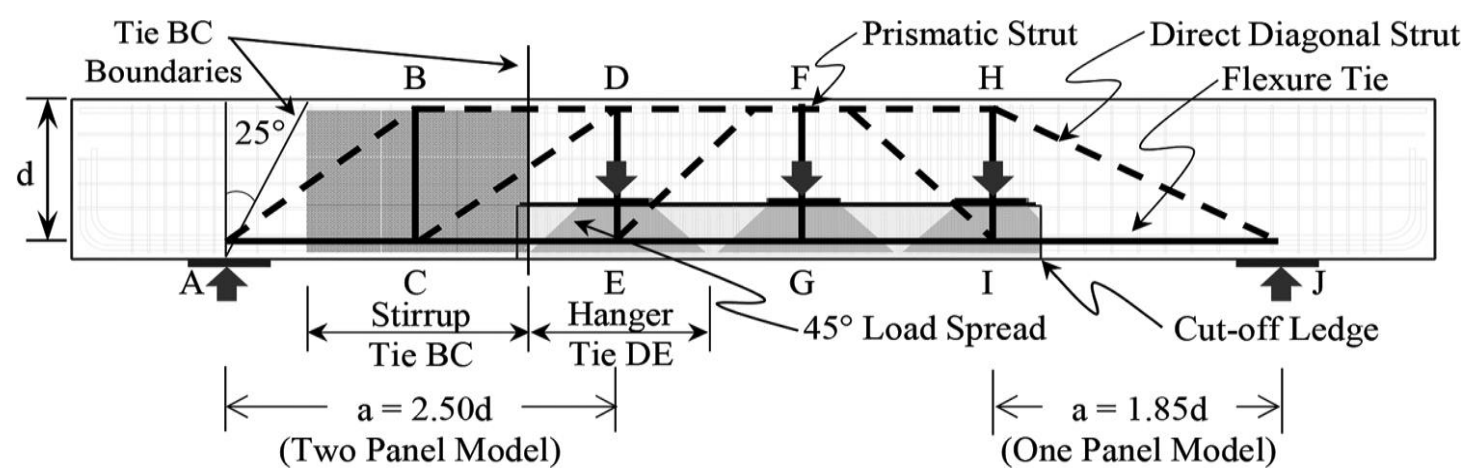

Fig. 9: Geometry of CCT Node A (Varney et al., 2015).

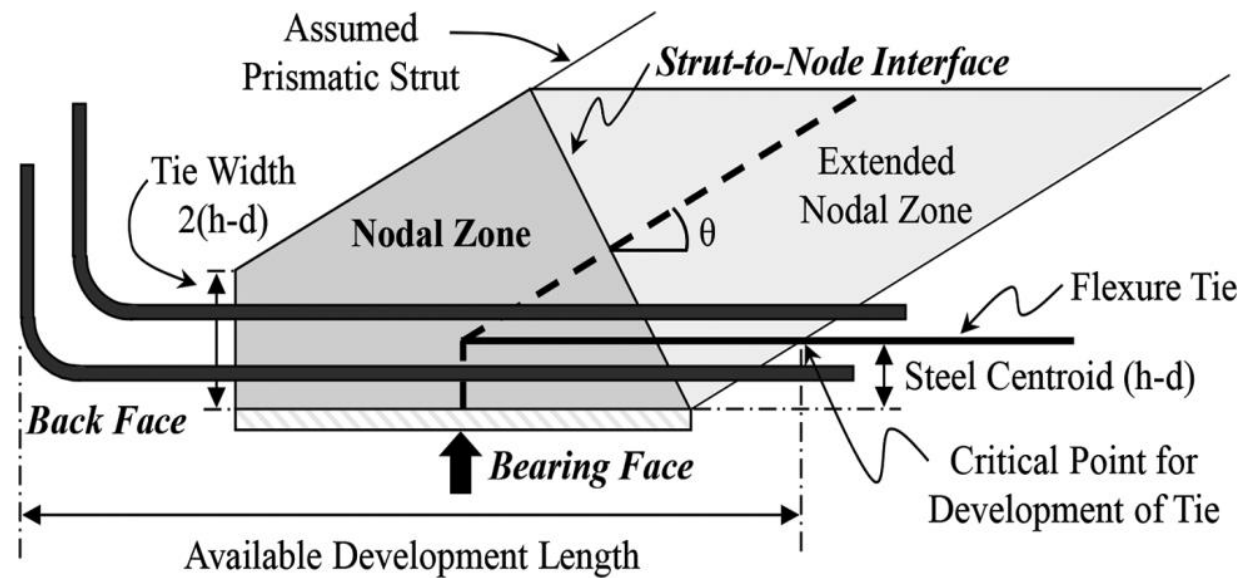

Fig. 10: Longitudinal strut-and-tie model for ledge beam (Varney et al., 2015).

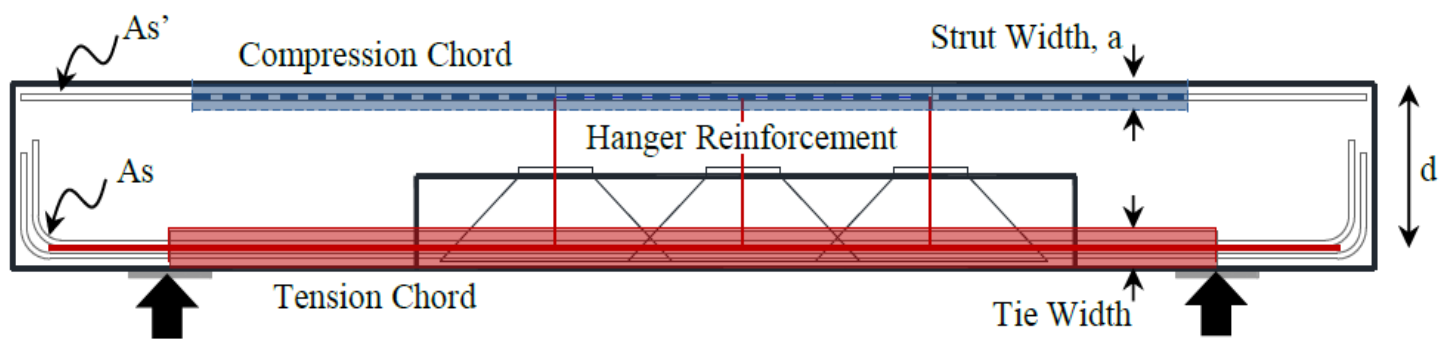

Fig. 11: Width and location of compression block and flexure tie (Larson et al., 2012).

Larson et al. (2012) determined the location of the intermediate tie BC in Figs. 9 and 11, for the two panel models in longer shear span using the technique proposed by Wight and Parra-montesinos (2003). In this technique, a line is projected at a 25-degree angle from the edge of the support plate at Node A to the top of the beam to define the limit of the tie. Tie BC is then centered halfway between the 45-degree projection from the loading plate at $\mathrm{DE}$ and the 25-degree projection from support plate at Node A, Fig. 9 (Varney et al., 2015).

Diagonal bottle-shaped struts, idealized as dashed lines, are then connected to complete the flow of forces in the longitudinal strut-and-tie model. The angles between the struts and ties should be checked to ensure that they are not less than 
25 degrees. Once the longitudinal model is completed, the forces in each element can be calculated using statics.

\subsection{Geometry of the transverse STM}

Along with the longitudinal model, a STM for the cross-section at each load point is required to design the ledge of any inverted T-beam. The external loads are applied equally to both sides of the web of the inverted T-beam or to one side of the Lbeam, Fig. 12. The hanger ties discussed in the longitudinal STM are located at the center of the vertical reinforcement. The closed loop ledge reinforcement is positioned next to the hanger reinforcement, with the top of the loop corresponding to the horizontal ledge tie. The centroid of the horizontal compression strut is positioned at the depth of the flexural reinforcement from the longitudinal model. A diagonal strut transfers the applied load from the loading plate to the bottom of the hanger reinforcement, as shown in Fig. 12 (Larson et al., 2012).

The angle between the diagonal strut and hanger bar must be checked to ensure it is greater than or equal to 25 degrees. If it is smaller, a wider or shallower ledge is required (Larson et al., 2012).

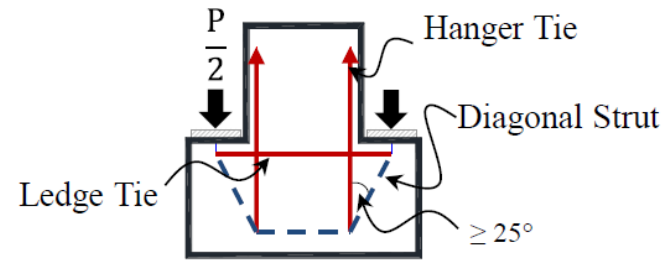

Fig.12: Cross sectional strut-and-tie model for ledge beam (Larson et al., 2012).

\subsection{STMs of Tested Specimens}

Using stress trajectories that was a result from 3D linear elastic finite element analysis, it was easy to develop STMs for the five specimens mentioned earlier, which are illustrated in table 4.The obtained capacity and predicted failure mode of the specimens using STM are given in table 5.

Table 4: STMs of tested specimens

\begin{tabular}{|c|c|c|c|c|c|}
\hline Specimen & \multicolumn{3}{c|}{ STM } \\
\hline SS1-75-1.85-06 & & & \\
\hline SS1-75-2.5-06 & & & \\
\hline
\end{tabular}




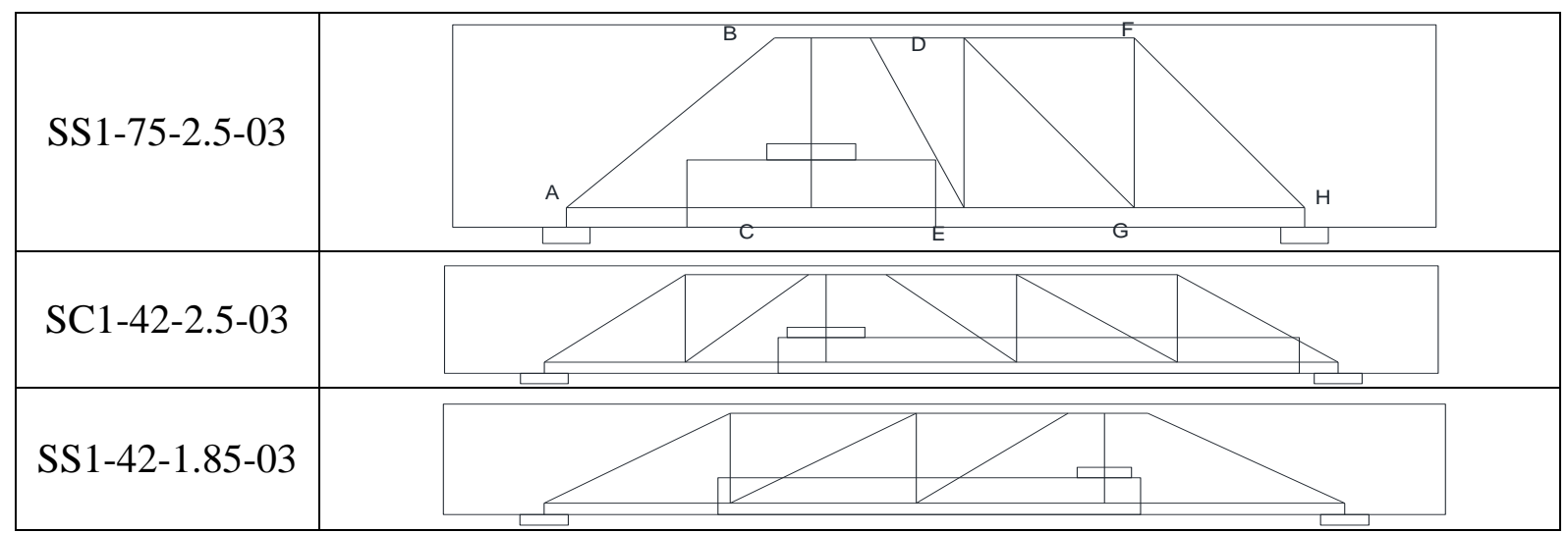

Table 5: Test, STM and NFEA results

\begin{tabular}{|c|c|c|c|c|c|c|c|c|}
\hline Specimen & \multicolumn{2}{|c|}{ Test Results } & \multicolumn{3}{|c|}{ STM Results } & \multicolumn{3}{|c|}{ NFEA Results } \\
\hline Specimen & $\begin{array}{l}P_{\text {test }} \text {, kip } \\
\quad(\mathrm{kN})\end{array}$ & $\begin{array}{l}\text { Mode of } \\
\text { failure }\end{array}$ & $\begin{array}{l}P_{S T M}, \text { kip } \\
\quad(\mathrm{kN})\end{array}$ & $\begin{array}{l}\text { Predicte } \\
\text { d mode } \\
\text { failure }\end{array}$ & $\frac{P_{\text {STM }}}{P_{\text {Test }}}$ & $\begin{array}{c}P_{F E M}, \\
\text { kip } \\
(\mathrm{kN})\end{array}$ & $\begin{array}{c}\text { Predicted } \\
\text { mode } \\
\text { failure }\end{array}$ & $\frac{P_{\text {NFEA }}}{P_{\text {Test }}}$ \\
\hline $\begin{array}{l}\text { SS1-75- } \\
1.85-06\end{array}$ & $\begin{array}{c}1826 \\
(8123)\end{array}$ & Punching & $\begin{array}{c}1200 \\
(5340)\end{array}$ & \multirow{5}{*}{ 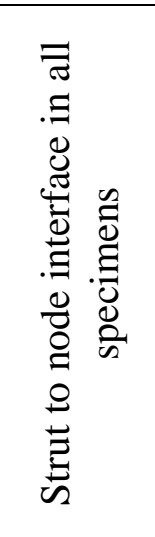 } & $(0.7)$ & $\begin{array}{c}1930 \\
(8590)\end{array}$ & Punching & 1.05 \\
\hline $\begin{array}{c}\text { SS1-75- } \\
2.5-06\end{array}$ & $\begin{array}{c}2125 \\
(9451)\end{array}$ & Punching & $\begin{array}{c}1295 \\
(5760)\end{array}$ & & $(0.65)$ & $\begin{array}{c}1900 \\
(8450)\end{array}$ & Punching & 0.9 \\
\hline $\begin{array}{c}\text { SS1-75- } \\
2.5-03\end{array}$ & $\begin{array}{c}1129 \\
(5023)\end{array}$ & Punching & $\begin{array}{c}1110 \\
(4940)\end{array}$ & & 1 & $\begin{array}{c}1285 \\
(5720)\end{array}$ & Punching & 1.1 \\
\hline $\begin{array}{c}\text { SC1-42- } \\
2.5-03\end{array}$ & $\begin{array}{c}506 \\
(2251)\end{array}$ & $\begin{array}{c}\text { Shear } \\
\text { Friction }\end{array}$ & $\begin{array}{c}520 \\
(2313)\end{array}$ & & 1 & $\begin{array}{c}620 \\
(2757)\end{array}$ & $\begin{array}{c}\text { Shear } \\
\text { Friction }\end{array}$ & 1.2 \\
\hline $\begin{array}{c}\text { SC1-42- } \\
1.85-03\end{array}$ & $\begin{array}{c}620 \\
(2757)\end{array}$ & $\begin{array}{c}\text { Yield of } \\
\text { Ledge } \\
\text { Tie }\end{array}$ & $\begin{array}{c}520 \\
(2313)\end{array}$ & & 0.85 & $\begin{array}{c}600 \\
(2670)\end{array}$ & $\begin{array}{l}\text { Yield of } \\
\text { Ledge Tie }\end{array}$ & 0.95 \\
\hline
\end{tabular}

\section{NFEA of Tested Specimens}

With reference to Fig. 13, the specimens have been analyzed under the concentrated test load, which is divided on the two ledges simultaneously with the same rate. All specimens have two supports one support is prevented from translation in the $y$ - and $\mathrm{x}$-directions, while the other support is prevented from translation in y direction only, $y$ designates vertical and $x$ designated horizontal. As a result of the symmetry of the specimens about the $\mathrm{z}$-axis only half of each specimen was considered in the analysis as shown in Fig. 14, where $\mathrm{z}$ designates out of plane. A finite element mesh has been developed so that the average aspect ratio was 1.05 as shown in Fig. 13. The loading protocol was a displacement control which the specimen will deflect until failure as shown in Fig. 15. Both linear and nonlinear analysis have been performed for the beams. The linear analysis has been conducted to show the stress trajectories and to compare with the proposed strut-and-tie models. The nonlinear analysis has been performed to predict the behavior of ledges such as: capacity, mode of failure, displacements, strains and stresses, at any step of loading. The stress trajectories obtained from the linear elastic analysis are shown in Fig. 16 and the results obtained from the nonlinear analysis are given in tables 5 and 6 . The results of finite element analysis are discussed in the following sections. 


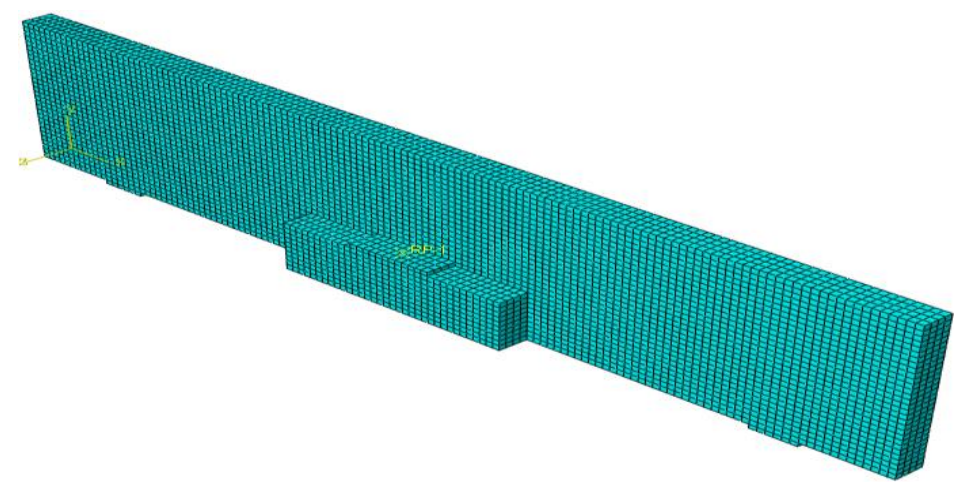

Fig. 13: Element modeling and the shape of mesh.

The beam is symmetric about $\mathrm{Z}$ axis (movements in $\mathrm{Z}$ direction is prevented and permitted in $\mathrm{X}$ and $\mathrm{Y}$ directions)

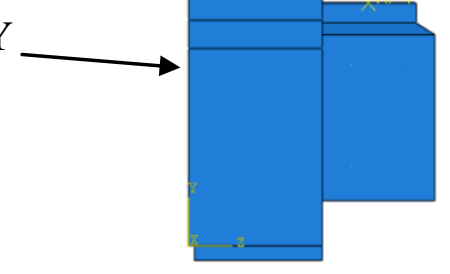

Fig. 14: Boundary Condition of symmetric condition.

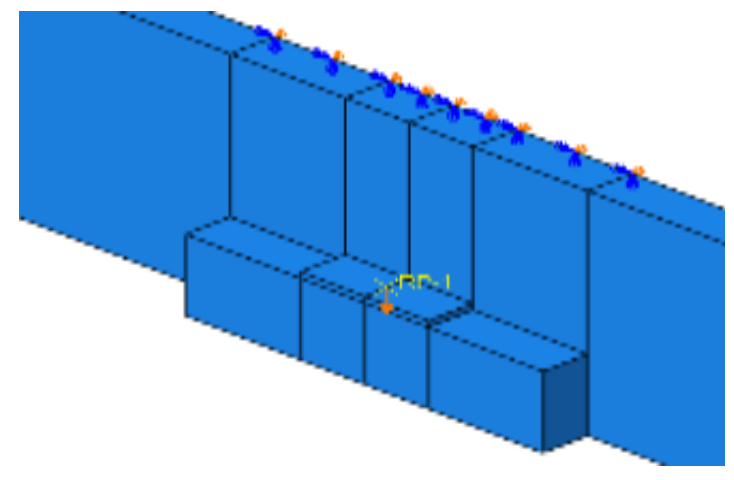

Fig. 15: Displacement control method for loading.

As observed from the results of the NFEA, punch failure was the main cause of failure of the specimens SS1-75-1.85-06, SS1-75-2.5-06 and SS1-75-2.5-03. Failure happened in the ledge as the diagonal cracking appeared on the face of the ledge extending from the edges of the bearing plates until the ledges were punched, table 6. Neither the bottom nor the top longitudinal bars reached yield in all the specimens except specimen SC1-42-1.85-03. In this specimen, the ledge reinforcement almost reached its yield strength; therefore, it is considered to have failed by yield of ledge tie reinforcement. The failure mode in specimen SC1-422.5-03 was shear friction of the ledge out of the web. Table 6 gives a comparison 
between the failure mode in NFEA and experimental tests. The failure loads according to the 3D NFEA is presented in table 5. The stress trajectories obtained from the finite element analysis have the same pattern for all specimens, therefore the results one specimen only is presented in Fig. 16, specimen SS1-75-1.85-03. Accordingly, the STM for all specimen were produced and shown in table 4.
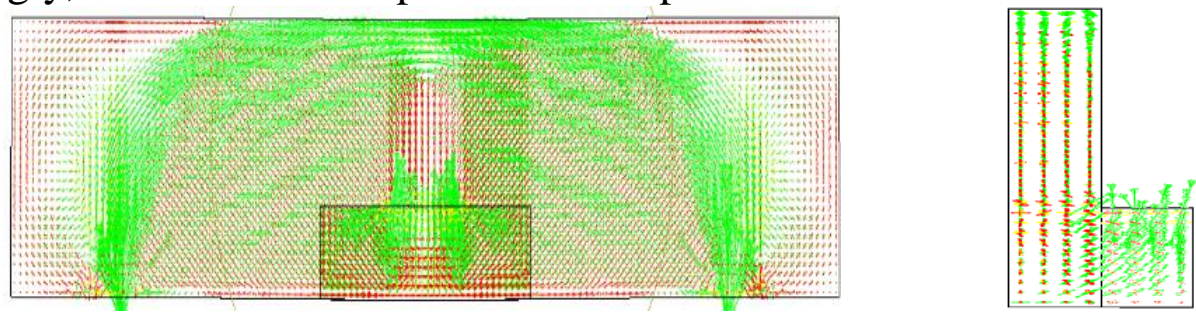

Fig. 16: Stress trajectories in longitudinal and cross section.

Table 6: comparison between modes failure according to ABAQUSE with real test

\begin{tabular}{|c|c|c|}
\hline \multirow{2}{*}{$\begin{array}{c}\text { Specimens } \\
\end{array}$} & \multicolumn{3}{|c|}{ Modes of Failure for specimens } \\
\hline $\begin{array}{c}\text { SS1-75-1.85-06 } \\
\text { (punching) }\end{array}$ & Experimental tests [9] \\
\hline $\begin{array}{c}\text { SS1-75-2.5-06 } \\
\text { (punching) }\end{array}$
\end{tabular}


Fig. 17 shows the load-displacement curves of four specimens from tests (Fernández-Gómez, 2012), and from the NFEA.From the given results, it is obvious that the NFEA solutions are very close to the test results.

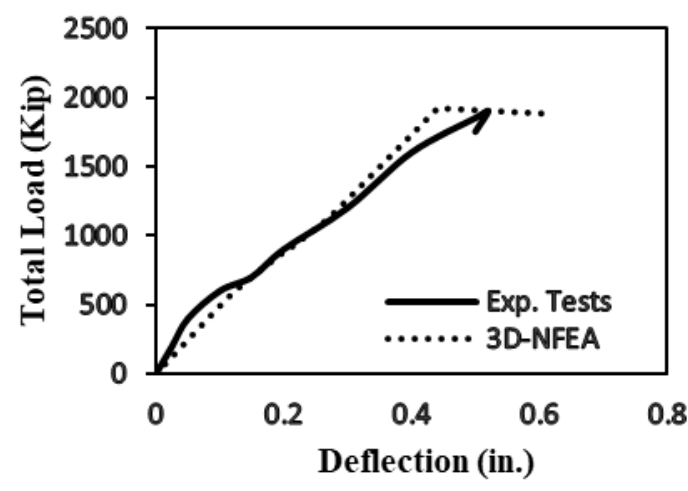

(a) Specimen SS1-75-1.85-06

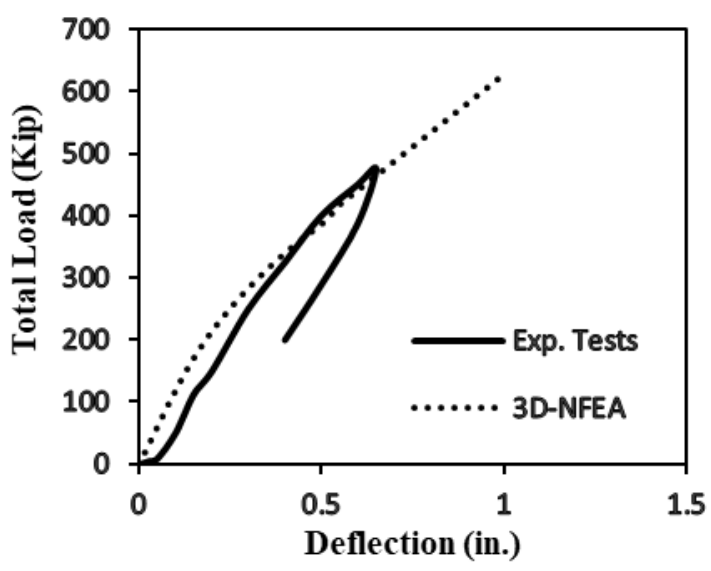

(c) Specimen SC1-42-2.5-03

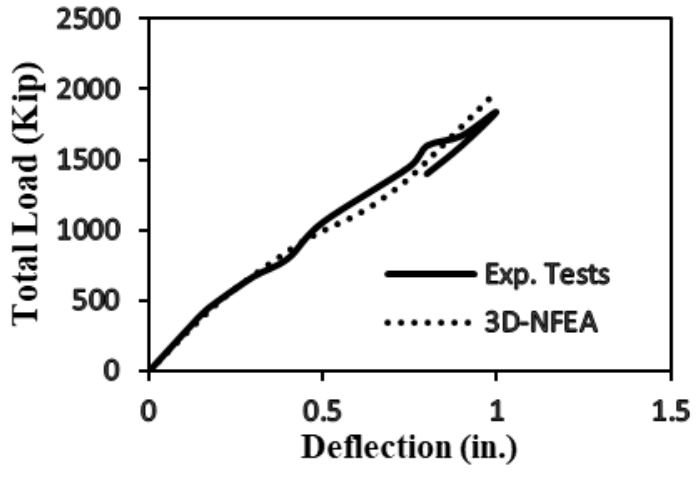

(b) Specimen SS1-75-2.5-06

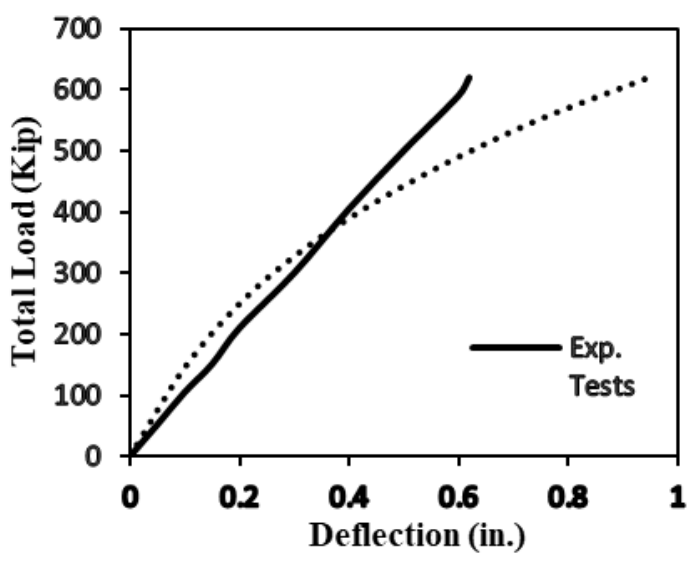

(d) Specimen SC1-42-1.85-03

Fig. 17: Load-displacement curves for real test and FE simulation.

\section{Results Interpretation}

According to table 5 the ratio between failure load estimated by STM and failure load measured in the test, $\left(P_{S T M} / P_{\text {Test }}\right)$, has a maximum value of 1.0 and a minimum value of 0.65 , with a mean ratio 0.83 . This ratio is logic since the STM leads to a lower bound solution. On the other hand, the ratio between failure load obtained by NFEA and that experimental values, $\left(P_{N F E A} / P_{\text {Test }}\right)$, has a maximum value of 1.2 and a minimum value of 0.9 with a mean ratio of 1.05 , which means that the NFEA gives more accurate prediction of the failure load than STM.

\section{Conclusions}

The results presented in this paper demonstrate the use of the method of strut-andtie model in developing a reliable and safe design. On the other hand, the nonlinear finite element analysis can serve in the optimization of the design capacity; in addition, it helps design engineers in the initial process of design and in obtaining 
important performance parameters such as deflection and stresses. Hence, it can be concluded that the two methods, STM and NFEA can serve as good companion tools in the design process.

\section{References}

1. Abaqus 6.13, Analysis User's Guide Volume III: Materials, 2015.

2. Abaqus 6.14, Analysis User'S Guide, Volume IV: Elements, 2016.

3. ACI Committee 318, Building Code Requirements for Structural Concrete (ACI 318-14) and Commentary, American Concrete Institute, Farmington Hills, MI, 2014, 519 p.

4. Broo, H., Lundgren, K., and M. Plos, M., "A guide to non-linear finite element modelling of shear and torsion in concrete bridges," Department of Civil and Environmental Engineering, Division of Structural Engineering, Concrete Structures, Chalmers University of Technology, Göteborg, Sweden, pp. 37, 2008.

5. Chaudhari, S. V., and Chakrabarti, M. A., "Modeling of Concrete for Nonlinear Analysis using Finite Element Code ABAQUS," International Journal of Computer Applications, Appl., V. 44, no. 7, pp. 1418, Apr. 2012.

6. El-Metwally, S. E., and Chen, W.F., "Structural Concrete: Strut-and-Tie Models for Unified Design," CRC Press, New York, 2017.

7. Fernández-Gómez, E., "Design criteria for strength and serviceability of inverted-T straddle bent caps," Ph.D. thesis, Univeristy of Texas at Austin, 2012.

8. Garber, D. B., Varney, N. L., Fernández-Gómez, E., and Bayrak, O., "Performance of Ledges in Inverted-T Beams," ACI Structural Journal, V. 114, No. 2, March-April 2017, pp. 487-498.

9. Jankowiak, T. and Lodygowski, T., "Identification of Parameters of Concrete Damage Plasticity Constitutive Model," Institute of Structural Engineering, Poznan University of Technology, Poland, Report No. 6, 2004.

10. Larson, N., Fernández-Gómez, E., Garber, D., Bayrak, O., and Ghannoum, W., "Strength and Serviceability Design of Reinforced Concrete Inverted-T Beams," Report No. 0-6416, Center for Transportation Research, University of Texas at Austin, Austin, TX, pp. 234, 2012.

11. Reineck, K. H., 2002, Ed., "Examples for the Design of Structural Concrete with Strut-and-Tie Models", SP-208, American Concrete Institute, Farmington Hills, MI, p. 242.

12. Schlaich, J. and Schäfer K., 1993, "The Design of Structural Concrete", IABSE Workshop, New Delhi. 
13. Schlaich, J.; Schäfer, K.; and Jennewein, M., "Toward a Consistent Design of Structural Concrete," Journal of the Prestressed Concrete Institute, V. 32, No. 3, May-June, 1987, pp. 74-150.

14. Sümer, Y., and Aktaş, M., "Defining parameters for concrete damage plasticity model," Challenge Journal of Structural Mechanics, vol. 1, no. 3, pp. 149-155, 2015.

15. Tan, K. H., Weng, L. W., and Teng, S., "A Strut-and-Tie Model for Deep Beams Subjected to Combined Top-and-Bottom Loading," The Structural Engineer, V. 75, No. 13, July 1997, pp. 215-222.

16. Varney, N. L., Fernández-Gómez, E., Garber, D. B., and Ghannoum, W. M., andBayrak, O., "Inverted-T beams: Experiments and strut-and-tie modeling," ACI Struct. J., vol. 112, no. 2, pp. 147-156, 2015.

17. Wight, J. K., and MacGregor, J. G, Reinforced Concrete: Mechanics and Design, 6th Ed., Pearson: New York, 2012.

18. Wight, J. K., and Parra-montesinos, G. J., "Strut-and-Tie Model for Deep Beam Design - A practical exercise using Appendix A of the 2002 ACI Building Code," Concrete international, May 2003.

19. Williams, C., Deschenes, D., and Bayrak, O. "Strut-and-Tie Model Design Examples for Bridges," Center for Transportation Research, The University of Texas at Austin, Austin, TX, pp. 276, 2012.

20. Tao, Z., Wang, Z. B., Yu, Q. "Finite element modelling of concrete-filled steel stub columns under axial compression," Journal of Constructional Steel Research, V. 89, pp121-131, 2013.

\section{Appendix (Estimation of Failure Load According to STM for Specimen SC1-42-2.5-03) \\ Cross Section STM}

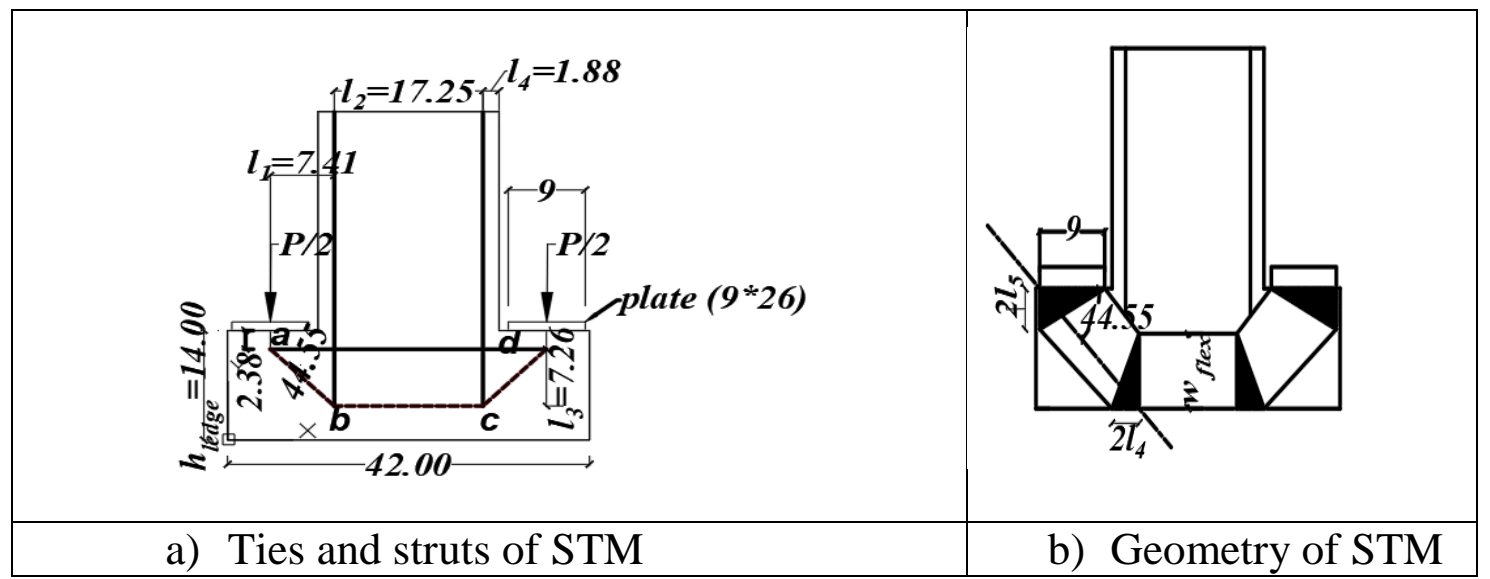




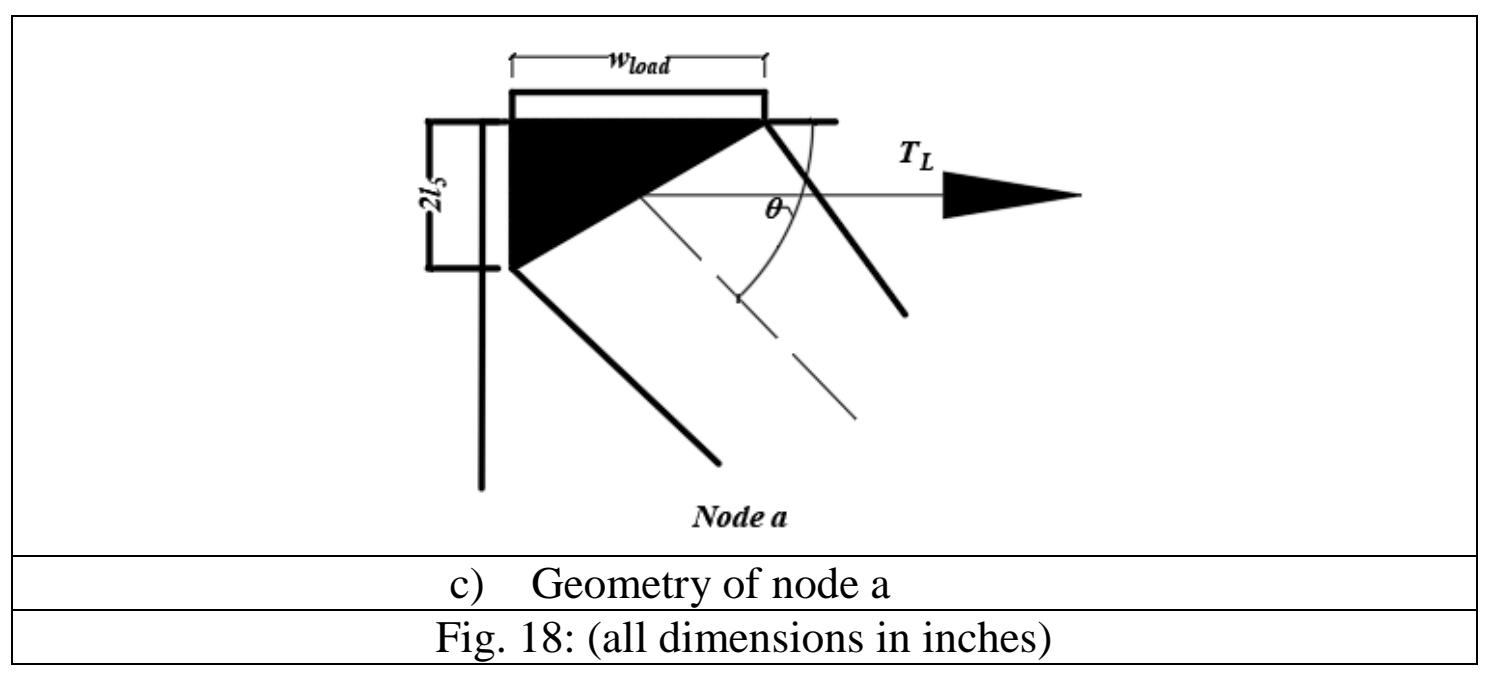

\section{a) Input}

The ledge tie reinforcement, $A_{s l}=\frac{32}{3} * 0.44=5.28 \mathrm{in}^{2}$ and the hanger steel, $A_{s h}=\frac{32}{3} * 0.44=5.28 \mathrm{in}^{2}$. The cylinder compressive strength of concrete, $f_{c}^{\prime}$ and the yield stress of the hanger steel, $f_{y h}$ and ledge tie steel, $f_{y l}$ are as given in table 3

\section{b) Geometry}

$w_{\text {suuport }}=20 \mathrm{in}$.

$$
w_{\text {load }}=9 \mathrm{in} .
$$

$l_{\text {support }}=16$ in. $_{\text {load }}=26 \mathrm{in}$.

$b_{\text {ledge }}=10.5 \mathrm{in} . \quad h_{\text {ledge }}=14 \mathrm{in}$.

$b_{\text {web }}=21 \mathrm{in} . h_{\text {web }}=42 \mathrm{in}$.

$d_{6}=0.75 \mathrm{in} . \quad d_{11}=1.41 \mathrm{in}$.

Web cover $=1.5 \mathrm{in}$. ledge cover $=2 \mathrm{in}$.

$w_{\text {flex. }}=\left(\right.$ web cover $\left.+\emptyset_{\text {st }}\right) * 2+n \emptyset_{\text {flex. }}+(n-1) * s$ $=(1.5+0.75) * 2+4 * 1.41+3 * 1.41=8.73 \mathrm{in}$.

$l_{1}=\frac{w_{\text {load }}}{2}+1+l_{4}=\frac{9}{2}+1+1.875=7.375 \mathrm{in}$.

$l_{2}=b_{w e b}-\left(2 * l_{4}\right)=21-(2 * 1.875)=17.25 \mathrm{in}$.

$l_{3}=h_{\text {web }}-\frac{w_{\text {flex. }}}{2}-l_{5}=14-\frac{8.73}{2}-2.375=7.26 \mathrm{in}$.

$l_{4}=\frac{\emptyset_{s t}}{2}+$ web cover $=\frac{0.75}{2}+1.5=1.875 \mathrm{in}$.

$l_{5}=\frac{\emptyset_{L T}}{2}+$ ledge cover $=\frac{0.75}{2}+2=2.375 \mathrm{in}$.

$\theta=\tan ^{-1}\left(\frac{l_{3}}{l_{1}}\right)=\tan ^{-1}\left(\frac{7.26}{7.375}\right)=44.55 \mathrm{deg}$. 


\section{c) Effective Concrete Strength of Struts}

The effective concrete strength of strut, $f_{c e}^{s}=0.85 f_{c}^{\prime} \beta_{s}$ For a prismatic strut, $f_{c e}^{s}=0.85 * 4.3 * 1=3.655 \mathrm{ksi}$.

For a strut of bottle-shaped stress field, $f_{c e}^{s}=0.85 * 4.3 * 0.75=2.74 \mathrm{ksi}$.

For struts in tension members, or the tension flanges of members, $f_{c e}^{s}=0.85 * 4.3 * 0.4=1.46 \mathrm{ksi}$.

d) Effective Concrete Strength of The Nodes

The effective concrete strength of a node, $f_{c e}^{n}=0.85 f_{c}^{\prime} \beta_{n}$ (or $0.67 f_{c u} \beta_{n}$ )

For $\mathrm{C}-\mathrm{C}-\mathrm{T}$ node, $f_{c e}^{n}=0.85 * 4.3 * 0.8=2.824 \mathrm{ksi}$.

For $\mathrm{C}-\mathrm{T}-\mathrm{T}$ node, $f_{c e}^{n}=0.85 * 4.3 * 0.6=2.2 \mathrm{ksi}$.

e) Modal Geometry and Forces

With reference to Fig. 18 and assuming that ledge tie reinforcement $A_{s l}$ reaches its yield,

$T_{l}=A_{s l} * f_{y l}=5.28 * 68.7=361$ kip.

The strut force $F_{a b}=T_{l} / \cos \theta=506.6$ kip.

The bearing load $F_{a}=\frac{P}{2}=F_{a b} * \sin \theta=355.4$ kip.

From equilibrium of node $\mathrm{b}$, the hanger load, $F_{h}=\frac{P}{2}=355.4$ kip.

Then the total failure load, $\mathrm{P}=355.4 * 2=710.8$

\section{f) Check the Bearing of The Nodes}

For node a, the nominal value of half the load $\frac{P}{2}=10 * 30 * 2.824=848$ Kip which is greater than the force $F_{a}, F_{a}=506.6$ Kip.

\section{g) Check of Stresses}

Node a:

Since the bearing stress has been checked before, there is no need to check it again. For strut ab, the inclination angle $=44.55$ degrees, and $w_{a b}=9 * \sin \theta+2 * 2.375 * \cos \theta=9.8 \mathrm{in}$. Then, the nominal strength of the strut is $C_{a b}=1.46^{\#} * 26 * 9.8=372 \mathrm{Kip}$. (\# the smaller of the node strength and the strut strength), which is smaller than the strut force. $C_{a b}=73.6 \% F_{a b}$ then the load has to be reduced, $\mathrm{P}=0.736 * 710.8=525 \mathrm{kip}$.

Hanger:

The nominal value of the hanger $T_{h}=A_{s h}{ }^{*} f_{y h}=5.28 * 71.4=377$ kip. Which is greater than the hanger force

Node b: 
As reinforcement properly developed until the extremities of the stress field in node $b$, it can be a smeared node that does not need to be checked. 